\title{
AGRONEGÓCIO E LOGÍSTICA EM ÁREAS DE CERRADO: EXPRESSÃO DA AGRICULTURA CIENTÍFICA GLOBALIZADA
}

Ricardo Castillo Professor do Programa de Pós-Graduação em Geografia - Instituto de Geociências da UNICAMP

Pesquisador do CNPq castillo@ige.unicamp.br

\section{Resumo}

O texto apresenta uma discussão sobre a infra-estrutura e a circulação de mercadorias e commodities agrícolas em particular, tanto para o mercado interno quanto para a exportação. A idéia-síntese que se impõe é a de competitividade da produção brasileira frente aos mercados internacionais. A análise recaiu sobre o papel do Estado e as políticas públicas de transporte e logística a partir da expansão e consolidação de fronteiras agrícolas em áreas de Cerrado do Centro Oeste, Norte e Nordeste.

Palavras-chave: Cerrado; Agronegócio, Biotecnologia; Commodities e Competitividade.

\begin{abstract}
This paper discusses the infrastructure and circulation of agricultural goods and commodities traded in the internal and export markets. The main idea that emerges from the text is the competitiveness of the Brazilian production performance in the international markets. The role of the State and public transportation policies and logistics are analyzed based on the expansion and consolidation of agricultural frontiers in the 'cerrado' areas located in the Center-West, North and Northeast regions of Brazil.
\end{abstract}

Key Words: Cerrado; agribusiness, biotechnology, commodities and competition.

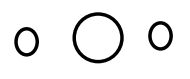

\section{INTRODUÇÃO}

Não se pode ignorar que o Brasil vivencia uma situação crítica em seus sistemas de transporte, armazenamento, aduaneiro, portuário e em quase tudo que diz respeito a infra-estruturas e legislação voltadas à circulação de mercadorias, commodities agrícolas em particular, tanto para o mercado interno quanto para a exportação. Termos como "gargalos logísticos" e "apagão logístico" saíram do ambiente corporativo especializado para ganhar a mídia (televisiva, eletrônica e impressa) e também tornar-se pauta prioritária de discussão, regulação e planejamento nos Ministérios e agências setoriais.

De fato, muita coisa está em jogo nesse conjunto de problemas, mas a idéiasíntese que se impõe é a de competitividade da produção brasileira frente aos mercados internacionais, ameaçada por razões logísticas.

Trata-se, portanto, de um problema de circulação (mais do que de produção propriamente dita), cujo encaminhamento parece seguir na direção de melhorar as condições da integração aos mercados externos - pelo menos essa tem sido a postura assumida por sucessivos governos (federal e estaduais), bem como por associações de classe e agências reguladoras setoriais.

Essa situação se traduz em políticas públicas de transporte e logística a partir da expansão e consolidação de fronteiras agrícolas em áreas de Cerrado do Centro Oeste, Norte e Nordeste, com intuito de viabilizar circuitos espaciais produtivos ${ }^{1}$ de algumas culturas de grande importância nos mercados internacionais. Nos últimos trinta anos, pode-se constatar um exponencial aumento dos fluxos materiais provenientes dessas porções do território brasileiro, marcadas pela emergência de regiões competitivas agrícolas, pela distância em relação aos principais centros consumidores do país e aos portos exportadores e pela baixa densidade em infra-estruturas logísticas. 


\section{DOIS PERÍODOS DA MODERNIZAÇÃO AGRÍCOLA NO BRASIL}

Para compreender o valor das novas variáveis que ordenam o território e interferem decisivamente nas políticas públicas e no planejamento propriamente dito, podemos recorrer a uma breve periodização da história recente da modernização agrícola no Brasil. Resumidamente, o primeiro período abrange aproximadamente as décadas de 1960 e 1970 e caracteriza-se pela constituição do chamado complexo agroindustrial $^{2}$. Esse paradigma é marcado pela forte presença do Estado na articulação entre os agentes envolvidos nos circuitos produtivos modernos, gerando uma maior aproximação e interdependência entre agricultura e indústria, com extensos subsídios a algumas categorias de produtores, incentivos fiscais, promoção da ocupação de novas fronteiras agrícolas e crédito, entre outras medidas, tais como o apoio à produção tecnológica (biotecnologia) e internalização de indústrias de bens de capital e de produção agrícolas.

O segundo período (o atual) é o de consolidação da produção de commodities nos Cerrados. A partir dos anos 1980, a forte crise fiscal do Estado brasileiro impele, pouco a pouco, a uma mudança nas formas de intervenção no setor agrícola. A adoção de políticas neoliberais (privatizações, concessões, diminuição dos subsídios, abertura comercial) junto a um novo paradigma produtivo dominante (com forte participação das tecnologias da informação) conduz a novas formas de relações entre os agentes da produção, sobretudo voltada à exportação ${ }^{3}$. O Estado renuncia, parcialmente, à sua posição de comando dos circuitos espaciais produtivos, e essa tarefa é assumida por grandes empresas do agronegócio. Podemos falar então de uma agricultura científica globalizada ${ }^{4}$.

Uma das características mais marcantes do atual período é a ocupação de milhões de hectares de Cerrado pela agricultura moderna globalizada ao mesmo tempo em que se aprofunda a divisão territorial do trabalho, expressa na forma de especialização regional produtiva.

Examinando-se somente a produção de grãos nas fronteiras agrícolas consolidadas, temos que Mato Grosso, Mato Grosso do Sul, Goiás e Bahia responderam, juntos, por um terço de toda a produção brasileira em 2003 (que, no total, superou 125 milhões de toneladas), segundo a Produção Agrícola Municipal do IBGE.

Dos trinta municípios maiores produtores de grãos do país, vinte e quatro localizam-se nas fronteiras agrícolas consolidadas; entre os dez primeiros, sete pertencem ao estado do Mato Grosso ${ }^{5}$. Um outro exemplo de concentração produtiva e especialização regional encontra-se no estado da Bahia: o município de São Desidério, localizado no cerrado baiano, respondeu por $24,3 \%$ do total de grãos produzido por essa unidade da federação ${ }^{6}$.

\section{ALGUMAS VARIÁVEIS-CHAVE DO ATUAL PERÍODO}

A regulação híbrida ${ }^{7}$ que caracteriza o atual uso do território brasileiro é marcada por um campo de forças que define investimentos em logística, envolvendo demandas corporativas e políticas públicas. Nesse sentido, parece cada vez mais importante reconhecer a interação entre três variáveis: 1) a expansão e consolidação da fronteira agrícola; 2) a emergência de regiões competitivas nessas áreas de fronteira; e 3) a predominância, no plano das idéias e também das ações, bem como nas políticas públicas e privadas, da logística.

Logística, na migração do sentido militar para o empresarial, tornou-se um termo escorregadio e polissêmico, empregado para designar variadas formas de prestação de serviços, condições gerais de produção, setor de atividade econômica, ramo de investimentos públicos entre outras. Na tentativa de compreender o termo em sua dimensão geográfica, propomos, por ora, defini-lo como o conjunto de competências 
infra-estruturais (transportes, armazéns, terminais intermodais, portos secos, centros de distribuição etc.), institucionais (normas, contratos de concessão, parcerias públicoprivadas, agências reguladoras setoriais, tributação etc.) e estratégicas (conhecimento especializado detido por prestadores de serviços ou operadores logísticos) que, reunidas num subespaço, podem conferir fluidez e competitividade aos agentes econômicos e aos circuitos espaciais produtivos. Trata-se da versão atual da circulação corporativa.

Região funcional ${ }^{8}$, por sua vez, sintetiza a emergência no período contemporâneo de um compartimento geográfico caracterizado pela especialização produtiva obediente a parâmetros externos (em geral internacionais) de qualidade e custos. Nela reconhecemos as idéias de competitividade e vulnerabilidade territoriais e, por isso, a região funcional aos mercados internacionais pode ser adjetivada como competitiva.

A especialização regional produtiva, isto é, a reunião de fatores produtivos e de condições particulares (serviços, armazenamento, terminais, comércio, centros de pesquisa e informação) numa determinada porção do território gera condições para o aumento da produção e da produtividade, elevando, portanto, a competitividade de alguns lugares e regiões para um determinado tipo de produção. Diante da internacionalização dos mercados e das finanças (e também dos custos e parâmetros produtivos), a competitividade regional torna-se obrigatória. No caso dos países periféricos, essa competitividade recai principalmente sobre a produção de commodities agrícolas (ou minerais). O "engessamento" dessas áreas que abrigam as monoculturas modernas, além das implicações conhecidas de concentração de terras, riqueza e renda, também pode gerar situações inusitadas. Um caso emblemático antecipa os conflitos que a expansão da cana-de-açúcar sobre culturas de grãos, por exemplo, pode gerar, além do agravamento de problemas ambientais já presentes na região Centro-Oeste. A Prefeitura do município de Rio Verde (GO), com o apoio de 47 entidades de classe, criou uma lei que limita em 10\% da área municipal destinada à agricultura, o cultivo da cana, sob a alegação de colocar em risco os investimentos já realizados e futuros vinculados às cadeias produtivas da soja e do milho (agroindústrias de óleo e farelo, frigoríficos, armazéns, criação de aves e suínos principalmente) ${ }^{9}$. Esse caso ilustra a vulnerabilidade de regiões funcionais atreladas aos mercados internacionais, sempre sujeitas a fatores externos que não podem controlar e nem mesmo prever.

Fronteira agrícola moderna, por fim e de maneira bastante simplificada, definese pelas áreas ocupadas por atividades agrícolas com alto conteúdo tecnológico e organizacional (em termos de uso de insumos e maquinário, formas de crédito e comercialização, armazenamento, beneficiamento e transporte) em substituição à pecuária extensiva, a formas tradicionais de cultura (particularmente a pequena produção familiar de origem ancestral ou de frentes de ocupação) e / ou à cobertura vegetal original.

Sinteticamente, a "equação" que reúne essas variáveis é a seguinte: a expansão de fronteiras agrícolas em áreas de Cerrado se consolida a partir do final dos anos 1970, com a emergência de regiões competitivas e a afirmação de circuitos espaciais produtivos dominados por grandes empresas do agronegócio, aumentando exponencialmente a demanda por logística, que, assim, se torna um subsetor estratégico.

Essas porções do território brasileiro reúnem características particulares (fisiográficas e geoeconômicas) ${ }^{10}$ que, num contexto de globalização econômica, as tornam mais aptas a receber o novo de maneira menos resistente, constituindo condições geográficas ideais para a política das grandes empresas, para além do processamento industrial e da comercialização.

As características edafo-climáticas e a topografia, de um lado, a grande concentração fundiária, a urbanização incipiente e dispersa, a baixa densidade em infra-estruturas, a distância em relação aos portos exportadores, um estoque de terras ainda a ser ocupado pelo agronegócio, de outro lado - tudo isso junto (num contexto de globalização econômica) criou possibilidades inéditas para a atuação de grandes empresas. 
São claros os círculos de cooperação estabelecidos entre as grandes empresas do agronegócio (Cargill, Bunge, ADM, Maggi, Coinbra, Caramuru entre outras), as empresas de logística (ALL, CVRD, Hermasa etc.) e o Estado.

Essas grandes empresas do agronegócio dominam, cada vez mais, o beneficiamento (classificação, limpeza, secagem), a assistência técnica, o processamento agroindustrial, o mercado de fertilizantes, o mercado de sementes, o armazenamento, o financiamento da produção, a comercialização e a exportação. Essas grandes empresas detém indústrias processadoras, armazéns e silos, empresas de colonização, empresas de comercialização de produtos agrícolas e seus derivados; atuam no transporte rodoviário, ferroviário, fluvial e marítimo, possuem terminais em portos fluviais e marítimos, centros de distribuição, escritórios exportadores, postos avançados de compra de grãos; fornecem crédito de custeio e investimento, prestam assessoria técnica a produtores conveniados, estabelecem parcerias com empresas de logística entre outras ações que variam segundo as especificidades do circuito de cada produto (soja, algodão, laranja, café, cacau, cana-de-açúcar estão entre os mais importantes).

A especialização regional produtiva em áreas de fronteira, além de implicações de ordem local (ambiental, econômica, social, política), também repercute na escala nacional através da geração de fluxos de grande volume e baixo valor agregado, numa porção do território distante dos centros consumidores e portos e desprovida de condições logísticas capazes de fazer frente às quantidades produzidas (medidas em dezenas de milhões de toneladas a cada safra).

Dessa situação emergem os alicerces, discursivos e práticos, técnicos e políticos, dos investimentos (públicos, privados e híbridos) em logística, traduzidos como demanda corporativa, mas também como estratégia territorial do Estado, visando à redução do custo-país e ao aumento da competitividade e da fluidez como garantia de exportação.

\section{Demandas corporativas}

Estamos nomeando aqui "demanda corporativa" a um conjunto de investimentos públicos, privados e híbridos (concessões e parcerias) que, na visão empresarial, poderia superar as deficiências em transporte, conferir competitividade e promover o crescimento do país. Nessa perspectiva, sugere-se que a politização da questão deve ser evitada e uma solução técnica deve ser encontrada para um problema igualmente considerado técnico.

Além de investimentos materiais, o encaminhamento da solução para os problemas logísticos, nessa visão, passa necessariamente pela produção de normas, particularmente naquilo que se convencionou chamar de marco regulatório, ou seja, é preciso evitar as "incertezas regulatórias". Em termos definitivos, argumenta-se que: a) faltam estabilidade e clareza às regras que dão garantias e segurança aos investidores

privados; b) é preciso diminuir as exigências para obtenção de licenças ambientais.

Parece cada vez mais claro que a era das concessões de serviços públicos a empresas privadas, que marcou os anos 1990, começa a ceder prioridade às Parcerias Público Privadas. Um Estado forte, antes capaz de propor um projeto nacional, deve ser substituído por Agências Reguladoras Setoriais despolitizadas e as decisões sobre investimentos migram cada vez mais para a esfera das grandes empresas.

Nesse passo, de um total de 504 projetos de infra-estrutura considerados prioritários pela demanda corporativa, somando R \$ 170,81 bilhões, cerca de 34\% devem ser destinados ao setor de transportes, perfazendo 228 obras $^{11}$. Dos investimentos em transportes, parcela considerável das obras consideradas prioritárias dirige-se ao escoamento da produção agrícola e agroindustrial das fronteiras consolidadas, rumo aos centros consumidores do Sul e Sudeste ou aos portos exportadores. 


\section{AGRICULTURA CORPORATIVA: TERRITÓRIO HIPOTECADO}

No momento atual, quando se produz tantos discursos que mais parecem querer confundir do que explicar, impõe-se ressaltar as diferenças essenciais entre o Estado e o Mercado. O Estado ainda é o único agente que tem responsabilidade com a totalidade do território e da sociedade, o que o distingue particularmente das grandes empresas, que usam os lugares, regiões e territórios (e suas populações) como recursos. Parece que se quer fazer acreditar que as injustiças, desperdícios e irracionalidades atribuídas ao Estado, no passado e no presente, serão resolvidos pela via do mercado.

É um risco muito grande, senão um total contra-senso, exigir do território e do Estado comportamentos de empresa e empresário. A política radical empreendida pela Prefeitura de Rio Verde (GO), na fronteira agrícola consolidada, expressa, ainda que de forma equivocada, a reação do poder público diante da vulnerabilidade a que as regiões funcionais agrícolas estão sujeitas.

Diante disso, algumas questões permanecem muito importantes: 1) como o avanço da agricultura corporativa influencia os investimentos em infra-estruturas no território brasileiro? 2) De que maneira as intervenções materiais e normativas que visam elevar os níveis de produtividade das empresas afetam o orçamento público nas três esferas de governo? 3) quais são as implicações disso para o conjunto da sociedade e para as populações locais?

\section{CONSIDERAÇÕES FINAIS}

Os investimentos em infra-estruturas no território brasileiro, incluindo energia elétrica, telecomunicações, abastecimento de água, saneamento básico e transportes, através de privatizações, concessões de serviços públicos a empresas privadas e parcerias público-privadas, estão se tornando, gradativamente, um grande negócio para poucas empresas.

Desde os anos 1990, o Estado brasileiro (em seus poderes executivo, legislativo e judiciário e nas escalas federal, estadual e municipal) vem oferecendo as condições para uma nova regulação que delega à iniciativa privada decisões estratégicas para o país e seu povo. A criação dessas condições, exigente tanto da produção de normas quanto de intervenção material no território, está para se completar, visto que ainda se prescreve a "despolitização" das agências reguladoras setoriais, entre outras medidas, para garantir à iniciativa privada a segurança requerida para investimentos de grande porte e longo prazo.

Dentro dessa lógica, ficam a cargo do Estado as obras pouco atrativas aos investimentos privados (aquelas cuja relação custo-benefício lhes seja desfavorável ou cujo mercado pareça insolvente), mas que repercutem positivamente no índice de competitividade do país.

Todos os discursos e justificativas que têm algo de neoliberal, tais como a ineficiência, a lentidão e a corrupção como qualidades intrínsecas ao Estado ou a modernidade, eficiência e rapidez da iniciativa privada, ganham consistência na particular combinação de características que marcam o Brasil: um território de dimensões continentais na periferia do sistema capitalista; desigualmente equipado em infraestruturas; com fundos territoriais ${ }^{12}$ ainda a ser ocupados, explorados e valorizados; fronteiras agrícolas modernas recentemente consolidadas e com participação crescente na pauta de exportações; deficiências logísticas de todo tipo; matriz de transporte de carga desequilibrada em favor do modal rodoviário; um Estado com poucos recursos e orçamento restrito e pouco flexível, adepto da exportação como único caminho para a expansão econômica, bem ao estilo do pensamento único da globalização ${ }^{13}$. Um quadro singular no mundo, cujas implicações ainda não foram totalmente analisadas. 
Nessa situação, vão sendo definidas as prioridades de investimentos em infraestruturas, de acordo com interesses corporativos, disfarçados pelo discurso de um desenvolvimento econômico que, automaticamente, beneficiaria toda a população.

Somos forçados a concordar com Araújo ${ }^{14}$ quando afirma, de maneira muito arguta, que o país caminha para uma desintegração competitiva e, sem nenhuma contradição, também concordamos com Ricupero ${ }^{15}$ quando sugere que a integração externa não precisa ser sinônimo de desintegração interna.

Com isso, não estamos querendo dizer que o Estado não investe absolutamente nada em setores e regiões que atendam os interesses de parcela majoritária da população ou do universo de pequenas e médias empresas, no que compete à logística e aos transportes. Pretendemos, isso sim, chamar a atenção para um conjunto de fatos que consideramos muito relevante, cujo sentido se encontra na tese de que as políticas públicas devem reassumir seu papel norteador no destino do território e da sociedade, a despeito das correntes que pregam a adaptação à globalização a todo custo.

Dentro da atual estrutura regulatória, expressa num jogo de forças que inclui as grandes empresas e diversas modalidades de organização da sociedade civil, o Estado é o único agente que tem responsabilidade sobre a totalidade do território e da população e esse seu papel não pode ser ameaçado.

\section{NOTAS}

(1) Com base em M. Santos (1988), A. C. R.Moraes (1991), M. Santos \& M. L. Silveira (2001) e M. Arroyo (2005), podemos afirmar que os circuitos espaciais produtivos "pressupõem a circulação da matéria (fluxos materiais) no encadeamento das instâncias geograficamente separadas da produção, distribuição, troca e consumo, de um determinado produto, num movimento permanente; os círculos de cooperação no espaço, por sua vez, tratam da comunicação, consubstanciada na transferência de capitais, ordens, informação (fluxos imateriais), garantindo os níveis de organização necessários para articular lugares e agentes dispersos geograficamente" (FREDERICO; CASTILLO, 2004).

(2) G. Muller. Complexo agroindustrial e modernização agrária. São Paulo: Hucitec / Educ 1989; J. G. da Silva. A nova dinâmica da agricultura brasileira. $2^{a}$ ed. rev. Campinas, SP: Unicamp, IE, 1998; L. Mazzali. O processo recente de reorganização agroindustrial: do complexo à organização "em rede". São Paulo: Editora Unesp, 2000.

(3) R. Castillo. Exportar alimentos é a saída para o Brasil? O caso do complexo soja. In: E. S. Albuquerque (org.). Que país é esse? Pensando o Brasil contemporâneo. São Paulo: Globo, 2005.

(4) M. Santos. Por uma outra globalização. Rio de Janeiro: Record, 2000.

(5) Mato Grosso é o maior produtor brasileiro de soja, milho e algodão. Entre seus municípios, destacam-se Sorriso (maior produtor nacional de soja), Lucas do Rio Verde (maior produtor nacional de milho) e Campo Verde (maior produtor nacional de algodão herbáceo). Fontes: Produção Agrícola Municipal do IBGE e A. Tsuneshiro. Os municípios brasileiros maiores produtores de grãos. São Paulo: Instituto de Economia Agrícola, APTA, Secretaria de Agricultura e Abastecimento do Governo do Estado de São Paulo, 2005.

(6) PAM / IBGE e Tsuneshiro (2005).

(7) R. Mendes Antas Jr. Território e regulação: espaço geográfico como fonte material e não-formal do direito. São Paulo: Humanitas / Fapesp, 2005.

(8) M. Santos. Técnica, espaço, tempo. São Paulo: Hucitec, 1994.

(9) www.globo.com/jornaldaglobo - site consultado em 14/11/2006.

(10) De um lado, características edafo-climáticas e topografia, de outro, a grande concentração fundiária, a urbanização incipiente e dispersa, a baixa densidade em infra-estruturas, a distância em relação aos portos exportadores, um estoque de terras ainda a ser ocupado pelo agronegócio. 
(11) Exame Infra-Estrutura, 2005/2006.

(12) A. C. R. de Moraes. Território e história no Brasil. São Paulo: Hucitec, 2002.

(13) M. Santos. Por uma outra globalização. Rio de Janeiro: Record, 2000.

(14) T. Bacelar Araújo. Dinâmica regional brasileira nos anos noventa: rumo à desintegração competitiva?. In: I. E. de Castro et al. (orgs.). Redescobrindo o Brasil: 500 anos depois. Rio de Janeiro: Bertrand Brasil, 2000.

(15) R. Ricupero. Integração externa, sinônimo de desintegração interna? Estudos Avançados 14 (40), 2000.

\section{REFERÊNCIAS BIBLIOGRÁFICAS}

ANTAS JR., R. Mendes. Território e regulação: espaço geográfico como fonte material e não-formal do direito. São Paulo: Humanitas / Fapesp, 2005.

ARAÚJO, T. Bacelar. Dinâmica regional brasileira nos anos noventa: rumo à desintegração competitiva?. In: I. E. de Castro et al. (orgs.). Redescobrindo o Brasil: 500 anos depois. Rio de Janeiro: Bertrand Brasil, 2000.

ARROYO, M. Fluidez e porosidade do território brasileiro no contexto da integração continental. In: M. L. Silveira (org.). Continente em chamas: globalização e território na América Latina. Rio de Janeiro: Civilização Brasileira, 2005 .

CASTILLO, R. Exportar alimentos é a saída para o Brasil? O caso do complexo soja. In: E. S. Albuquerque (org.). Que país é esse? Pensando o Brasil contemporâneo. São Paulo: Globo, 2005.

EXAME INFRA-ESTRUTURA, 2005/2006.

FREDERICO, S; CASTILLO. R. Circuito espacial produtivo do café e competitividade territorial no Brasil. Ciência Geográfica. Bauru, Ano X, Volume X, no 3:236-241, 2004.

MAZZALI, L. O processo recente de reorganização agroindustrial: do complexo à organização “em rede”. São Paulo: Editora Unesp, 2000.

. Los circuitos espaciales de la producción y los círculos de cooperación en el espacio. In: Aportes para el estúdio del espacio socioeconômico, tomo III, El Coloquio, org. L. Yanes et al. Buenos Aires: [s.n.], 1991.

Território e história no Brasil. São Paulo: Hucitec, 2002.

MULLER. G. Complexo agroindustrial e modernização agrária. São Paulo: Hucitec / Educ 1989.

PAM / IBGE e Tsuneshiro (2005).

RICUPERO, R. Integração externa, sinônimo de desintegração interna? Estudos Avançados 14 (40), 2000.

SANTOS, M. Metamorfoses do espaço habitado. São Paulo: Hucitec, 1988.

. Técnica, espaço, tempo. São Paulo: Hucitec, 1994.

. Por uma outra globalização: do pensamento único à consciência universal. Rio de Janeiro: Record, 2000.

.; SILVEIRA, M. L. Brasil: território e sociedade no início do século XXI. São Paulo: Record, 2001.

SILVA, J. G. da. A nova dinâmica da agricultura brasileira. 2ª ed. rev. Campinas, SP: Unicamp, IE, 1998. www.globo.com/jornaldaglobo - site consultado em 14/11/2006.

Recebido em maio de 2007

Aceito em agosto de 2007 